\title{
The acute cutaneous inflammatory response is attenuated in Slug-knockout mice
}

\author{
Kimberly M Newkirk ${ }^{1}$, F Jason Duncan² ${ }^{2}$ Erin M Brannick ${ }^{1}$, Heather L Chandler ${ }^{3}$, Allison E Parent ${ }^{1}$ and \\ Donna F Kusewitt ${ }^{1}$
}

We previously reported ultraviolet radiation (UVR) induction of Slug, a Snail family zinc-finger transcription factor, in the epidermis of mice; we now report that Slug-knockout mice are, unexpectedly, more resistant to sunburn than wild-type mice. There was a marked difference between the cutaneous inflammatory response in the skin of Slug-knockout and wild-type mice from $12 \mathrm{~h}$ to 1 week following a single exposure to 3 minimal erythemal doses of UVR. Slug-knockout mice showed a much reduced immediate increase in skin thickness and neutrophil infiltration compared to wild-type mice. However, there were as many or more intraepidermal T cells, dermal mast cells, and dermal blood vessels in the UVRexposed skin of Slug-knockout mice as in the skin of wild-type mice. Differences in cytokine and chemokine expression following UVR appeared to account for at least some differences between the genotypes in cutaneous inflammatory response. Despite the reported antiapoptotic and antiproliferative role for Slug in some cell types, we observed little difference between the genotypes in UVR-induced keratinocyte apoptosis or proliferation. Our findings indicate an unexpected but important role for Slug in the acute cutaneous inflammatory response to UVR.

Laboratory Investigation (2008) 88, 831-841; doi:10.1038/labinvest.2008.37; published online 5 May 2008

KEYWORDS: Slug; UV; inflammation; mice; skin

Slug (Snai2) belongs to the Snail family of transcription factors and is known to modulate epithelial-mesenchymal transformation (EMT), which is characterized by the transformation of anchored epithelial cells into migratory cells with a fibroblastic phenotype. ${ }^{1}$ EMT occurs normally during embryogenesis and is involved in neural crest cell migration and limb bud formation. ${ }^{1}$ Changes resembling EMT occur in the adult skin in keratinocytes at wound margins ${ }^{2}$ and in ultraviolet radiation (UVR)-induced squamous cell carcinomas. ${ }^{3}$ Slug has been shown to control these EMT-like events in adult keratinocytes in vitro, ex vivo, and in vivo. ${ }^{2}$ Slug also appears to play an important role in skin homeostasis, as indicated by Slug expression in normal adult epidermis ${ }^{4}$ and by substantial differences in basal gene expression between Slug-knockout and wild-type epidermis. ${ }^{5}$

The initial response of the skin to UVR is vasodilation of cutaneous blood vessels resulting in erythema and edema. This is closely followed by keratinocyte apoptosis and inflammatory cell infiltration. ${ }^{6}$ The magnitude and time course of these events depend upon the wavelengths and dose of
UVR delivered. We previously demonstrated dose-dependent UVR induction of Slug in keratinocytes. ${ }^{3}$ In addition, by identifying altered expression of various immunomodulatory factors in the untreated epidermis of Slug null mice, we were the first to suggest a potential role for Slug in the epidermal inflammatory response. ${ }^{5}$ In the present report, we document a marked difference between the inflammatory response of Slug-knockout and wild-type skin to UVR and provide evidence that this difference can be attributed, at least in part, to differences in the production of immunomodulatory factors by UVR-exposed epidermis.

\section{MATERIALS AND METHODS UVR Exposure of Mice}

The mice used in this study were wild-type mice and homozygous Slug-knockout mice on an inbred 129 background (129S1/SvImJ). Mice employed in these studies were generated and initially described by Dr Thomas Gridley (Jackson Laboratory, Bar Harbor, ME, USA). ${ }^{7}$ In these mice, the zinc-finger region of the Slug gene has been replaced by a

\footnotetext{
${ }^{1}$ Department of Veterinary Biosciences, College of Veterinary Medicine, The Ohio State University, Columbus, OH, USA; ${ }^{2}$ Department of Surgery, College of Medicine, The Ohio State University, Columbus, OH, USA and ${ }^{3}$ Department of Clinical Sciences, College of Veterinary Medicine, The Ohio State University, Columbus, OH, USA Correspondence: Dr KM Newkirk, PhD, Department of Veterinary Pathobiology, College of Veterinary Medicine, University of Tennessee-Knoxville, 2407 River Drive, Room A201, Knoxville, TN 37996-4543, USA.
}

E-mail: kmnewkirk@utk.edu

Received 18 July 2007; revised 06 February 2008; accepted 03 March 2008 
$\beta$-galactosidase gene, resulting in the production of a Slug- $\beta$ galactosidase fusion protein $\left(\right.$ Snai2 $\left.2^{\text {lacZ }}\right) .{ }^{7}$ The Slug portion of this protein is non-functional, as it lacks the zinc-finger region; however, the $\beta$-galactosidase portion of the protein is fully functional. Two female and one male 10- to 12-week-old mice of each genotype comprised each group, except the 12 and $24 \mathrm{~h}$ time points, which had six female mice and one male mouse per group.

UVR was obtained from Kodacel-filtered Westinghouse FS-40 lamps that emitted wavelengths between 280 and $400 \mathrm{~nm}$ with a peak at $313 \mathrm{~nm}$ (primarily UV-B). Based on determinations of skin thickness, $1600 \mathrm{~J} / \mathrm{m}^{2}$ represented 1 minimal erythemal dose (MED). For UVR exposures, the mice were shaved with electric clippers and depilated using Nair hair remover. Forty-eight hours later, the skin thickness of each mouse was measured. Skin thickness was determined by measuring the thickness of a skin tent with digital calipers in three different areas of the back; these individual values were then averaged. The entire mouse was then exposed to 3 MED of UVR. At 12, 24, 48, 72, and $96 \mathrm{~h}$ and 1 week post-UVR, skin thickness measurements were obtained immediately before carbon dioxide asphyxiation. After euthanasia, samples of skin were frozen in liquid nitrogen for RNA isolation and myeloperoxidase (MPO) measurement, and fixed in $10 \%$ neutral buffered formalin for histologic analysis. Given that the Slug-knockout mice are born at lower than the expected frequency, Slug-knockout mice and their age- and sex-matched wild-type counterparts were exposed as they became available, such that not all the exposures occurred concurrently.

\section{Histology and Immunohistochemistry}

Formalin-fixed samples were embedded in paraffin, sectioned at $4-5 \mu \mathrm{m}$ thickness, and stained with hematoxylin and eosin. Neutrophil counts were obtained by counting the number of segmented nuclei in six different $\times 400$ fields of dermis. Neutrophils in epidermal pustules and areas of dermal necrosis were excluded. Acid fast staining ${ }^{8}$ was used to identify dermal mast cells. Mast cell counts were obtained by counting the number of mast cells in six different $\times 400$ fields of dermis.

Immunohistochemistry was performed as follows for cleaved caspase 3, CD3, and Ki-67 antigens: slides were deparaffinized and rehydrated. Antigen retrieval was performed with DakoCytomation Target Retrieval Solution (Dako North America Inc., Carpinteria, CA, USA) and the Biocare Digital Decloaking Chamber (Biocare Medical, Concord, CA, USA) by heating under pressure to $125^{\circ} \mathrm{C}$ for $30 \mathrm{~s}$ followed by cooling in the chamber to $90^{\circ} \mathrm{C}$ and on the bench top for 10 min. Immunohistochemical staining was carried out using the Dako Autostainer. Slides were rinsed with water, and then treated for $5 \mathrm{~min}$ with $3 \%$ hydrogen peroxide and with protein block (DakoCytomation Serum-free Protein Block, Dako North America, Inc.) for $10 \mathrm{~min}$. Slides were incubated for 30 min with primary antibody diluted in DakoCytomation
Antibody Diluent with Background Reducing Components (Dako North America Inc.). Slides were incubated for $30 \mathrm{~min}$ with secondary antibody (Vector biotinylated goat-antirabbit or rabbit-anti-rat antibody; Vector Laboratories, Burlingame, CA, USA) diluted 1:200 in antibody diluent and for 30 min with $A B C$ reagent (Vector RTU Vectastain Elite ABC; Vector Laboratories). Slides were then incubated for $5 \mathrm{~min}$ in DakoCytomation Liquid DAB Substrate, counter-stained with hematoxylin, dehydrated, and coverslipped. Rinses were performed using DakoCytomation Wash Buffer (Trisbuffered saline/Tween-20). Antibodies included rabbit anti-cleaved caspase 3 (Cell Signaling Technology, Danvers, MA, USA) diluted 1:200, rabbit anti-CD3 (Dako North America Inc.) diluted 1:100, and rat anti-mouse Ki-67 diluted 1:100. Cells positive for cleaved caspase 3 or CD3 had cytoplasmic staining, whereas cells positive for Ki-67 staining had nuclear staining.

For immunohistochemical detection of $\mathrm{p} 53$, antigen retrieval was performed by steaming for $20 \mathrm{~min}$ in $1 \times$ Antigen Unmasking Solution (Vector Laboratories), followed by a 20-min cool down step. Blocking was performed with $1 \times$ casein (Vector Laboratories) for $30 \mathrm{~min}$ at room temperature. Slides were incubated for $1.5 \mathrm{~h}$ with rabbit polyclonal primary antibody (Novocastra Laboratories Ltd, Newcastle upon Tyne, UK) diluted 1:300 in $1 \times$ casein, for $30 \mathrm{~min}$ at room temperature with the secondary antibody (LINK Biotinylated AntiRabbit Immunoglobulins; Biogenex Laboratories Inc., San Ramon, CA, USA), for $30 \mathrm{~min}$ at room temperature with detection substrate (LABEL peroxidaseconjugated streptavidin; Biogenex Laboratories Inc.), and DAB (DAB Peroxidase substrate kit; Vector Laboratories) for $6 \mathrm{~min}$ at room temperature. A final distilled water rinse was performed before counterstaining with Mayer's hematoxylin for $1 \mathrm{~min}$, dehydrating, and coverslipping. All rinses were performed with Tris-buffered saline/Tween-20. Cells positive for p53 had strong nuclear staining. For cleaved caspase 3, $\mathrm{CD} 3, \mathrm{Ki}-67$, and p53, positive cells were counted in the epidermis of six different $\times 400$ fields. In each of these fields, the total number of epidermal cells was also counted, and the number of immunopositive cells was expressed as the percent of the total epidermal cells.

CD31 was detected immunohistochemically by deparaffinizing and rehydrating sections, blocking endogenous peroxidase with $3 \% \mathrm{H}_{2} \mathrm{O}_{2}$, treating with $0.06 \%$ protease 24 (Sigma, St Louis, MO, USA) for $10 \mathrm{~min}$ at room temperature, blocking nonspecific protein binding (TSA kit; Perkin Elmer, Waltham, MA, USA), incubating with primary antibody (rat anti-mouse CD31; BD Biosciences, San Jose, CA, USA) overnight at $4^{\circ} \mathrm{C}$, treating with secondary antibody (biotinylated rat anti-IgG; Vector Laboratories) for $30 \mathrm{~min}$ at room temperature, amplifying signal with biotinylated tyramide (TSA kit; Perkin Elmer), and developing color with diaminobenzidine (Sigma). Primary antibody was used at a dilution of 1:400, and secondary antibody was diluted 1:200. Blood vessels in the dermis were counted in each of six $\times 400$ 
fields, and the diameter of vessels was measured using an ocular micrometer.

For detection of cyclobutane pyrimidine dimers (CPDs), slides were deparaffinized and then hydrated to water. Antigen unmasking was performed by incubating slides in proteinase K (Qiagen DNeasy kit; Qiagen, Valencia, CA, USA) diluted 1:300 in phosphate-buffered saline (PBS) for $25 \mathrm{~min}$ at $37^{\circ} \mathrm{C}$, followed by a water rinse. Slides were then incubated in RNase A (USB Corporation, Cleveland, $\mathrm{OH}$, USA) diluted to $5 \mu \mathrm{g} / \mathrm{ml}$ in PBS for $20 \mathrm{~min}$ at $37^{\circ} \mathrm{C}$, followed by a PBS rinse. Blocking was performed with $3 \%$ hydrogen peroxide for $5 \mathrm{~min}$. Staining was continued using the Mouse On Mouse (MOM) kit (Vector Laboratories). Slides were incubated with MOM blocking reagent for $1 \mathrm{~h}$ at room temperature and preincubated in the MOM antibody diluent for $5 \mathrm{~min}$ before a 2-h room temperature incubation with primary anti-thymidine dimer antibody (Kamiya Biomedical Company, Seattle, WA, USA) diluted 1:50 in MOM diluent. Secondary antibody (MOM biotinylated secondary antibody) was applied to the slides for $10 \mathrm{~min}$ at room temperature. Slides were then incubated for $30 \mathrm{~min}$ at room temperature with detection reagent (LABEL peroxidase-conjugated streptavidin; Biogenex Laboratories Inc.) and with $\mathrm{DAB}$ (DAB peroxidase substrate kit; Vector Laboratories) for $5 \mathrm{~min}$ at room temperature before a final rinse with water. Slides were counterstained with Eosin Y (diluted to $25 \%$ in $100 \%$ ethanol) and then rinsed with 95\% ethanol, dehydrated, and coverslipped. Unless otherwise indicated, rinses were performed with PBS. CPD-positive cells had strong nuclear staining.

\section{Myeloperoxidase Assay}

For MPO analyses, two 5-mm skin punches from each mouse were placed in $1.25 \mathrm{ml}$ of $0.5 \%$ hexadecyltrimethylammonium bromide in $50 \mathrm{mM}$ potassium phosphate buffer ( $\mathrm{pH}$ 6.0) before homogenization. Samples were then sonicated for $10 \mathrm{~s}$, frozen in liquid nitrogen, and thawed at $37^{\circ} \mathrm{C}$ in a water bath; this was repeated twice. The samples were centrifuged for $30 \mathrm{~min}$ at 13000 r.p.m. and the supernatant was removed and allowed to come to room temperature. A $10 \mu \mathrm{l}$ portion of supernatant was added to $290 \mu \mathrm{l}$ substrate $(50 \mathrm{mM}$ phosphate buffer, $\mathrm{pH} 6.0$, with $0.167 \mathrm{mg} /$ $\mathrm{ml} o$-dianisidine dihydrochloride and $0.0005 \% \mathrm{H}_{2} \mathrm{O}_{2}$ ). MPO activity was measured, using a microplate reader, at a wavelength of $450 \mathrm{~nm}$ for $5 \mathrm{~min}$.

\section{RNA Isolation}

For RNA isolation, the epidermis was vigorously scraped from frozen skin samples, using a scalpel blade. Samples were placed in Trizol (Invitrogen, Carlsbad, CA, USA), then homogenized and processed as recommended by the supplier. Skin was fixed in formalin after scraping and examined histologically to confirm that the epidermis was completely removed. This technique isolates primarily keratinocytes and small numbers of Langerhans cells and intraepidermal dendritic cells that are resident in the epidermis. Wild-type and knockout samples were processed simultaneously. Highquality RNA was consistently isolated using this technique.

\section{Quantitative RT-PCR}

Total RNA from Slug-knockout and wild-type epidermis was used for real-time quantitative polymerase chain reaction (PCR). A $5 \mu \mathrm{g}$ portion of total RNA from each mouse was treated with DNaseI (Ambion, Austin, TX, USA), and cDNA was produced by reverse transcription of $500 \mathrm{ng}$ of this RNA using Superscript II (Invitrogen) and oligo(dT) primers, as directed by the manufacturer. Quantitative reverse transcription-PCR (RT-PCR) was performed using Brilliant SYBR Green QPCR mix (Stratagene, La Jolla, CA, USA) as directed with $100 \mathrm{nM}$ of each primer in an MX3000P RealTime PCR System (Stratagene). Fifty cycles of $94^{\circ} \mathrm{C}(30 \mathrm{~s})$, $60^{\circ} \mathrm{C}(30 \mathrm{~s})$, and $72^{\circ} \mathrm{C}(30 \mathrm{~s})$ were performed. RNA concentrations were calculated using the LinReg PCR program, which uses four points in the best linear region of amplification to determine starting mRNA concentration and PCR efficiency for each sample. ${ }^{9}$ GAPDH (forward sequence: TGATGACATCAAGAAGGTGAAC; reverse sequence: ATGG CCTTACATGGCCTCCAAGG) was used as an internal standard to account for efficiency of reverse transcription and amplification. Expression values for cyclooxygenase-2 (COX-2) (forward sequence: CCCCCACAGTCAAAGACACT; reverse sequence: GGTTCTCAGGGATGTGAGGA) were normalized to GAPDH values. For all analyses, three separate PCR runs were performed and averaged.

\section{Cytokine Array}

Epidermal RNA was purified using the RNeasy kit (Qiagen), and cRNA was prepared and purified using the TrueLabelingAMP 2.0 and Array Grade cRNA Cleanup kits, respectively (SuperArray Bioscience Corporation, Frederick, MD, USA). Two cRNA samples from female mice for each time point were pooled and applied to each membrane, and then hybridized by incubating overnight at $60^{\circ} \mathrm{C}$. Following the appropriate washings, detection was performed and images were captured using a CCD camera (Kodak IS200R, Rochester, NY, USA). The captured images were then analyzed using GEArray Expression Analysis Suite software (SuperArray Bioscience Corporation). Average spot intensity was determined by taking the total density and dividing by the number of pixels. Background was reduced globally; the total density value per area within the grid but outside of grid capture was used as the background correction value. A spot was considered 'absent' if the average density of the spot was less than 1.5 times of the mean value of the local backgrounds of the lower 75 percentile of all non-bleeding spots. All other spots are considered 'present.' All present spot intensities were normalized to the housekeeping gene GAPDH. Three arrays were performed for each genotype at both 12 and $24 \mathrm{~h}$ post-UVR; representing a total of six female mice of each genotype examined at each time point. 


\section{Statistics}

One-tailed Student's $t$-tests were performed for statistical evaluation of data. $P$-values of 0.05 or less were considered significant.

\section{RESULTS}

\section{Gross and Histologic Pathology}

At 12, 24, and $48 \mathrm{~h}$ following UVR exposure, wild-type mice had evidence of sunburn, characterized by redness, scaling, and peeling of the skin; however, this change was rarely observed in the Slug-knockout mice. By $72-96 \mathrm{~h}$ post-exposure, the areas of erythema on the wild-type mice had progressed to areas of hyperkeratosis or ulceration with serocellular crust formation (Figure 1); similar changes were not apparent in the knockout skin. One week following UVR exposure, the areas of ulceration on the wild-type mice had largely resolved.

The histologic changes following UVR exposure corresponded to those observed grossly (Figure 2 ). At $12 \mathrm{~h}$ postexposure, there were substantial neutrophil infiltrates in the dermis of the wild-type mice but only minimal infiltrates in the dermis of knockout mice. At this time point, both genotypes had minimal keratinocyte apoptosis and hyperkeratosis. By $24 \mathrm{~h}$ post-exposure, there was a dense neutrophil infiltrate in the dermis of wild-type mice and a much less marked dermal infiltrate in knockout mice. At $24 \mathrm{~h}$ postUVR, both genotypes had evidence of keratinocyte apoptosis, as demonstrated by pyknotic nuclei and hypereosinophilic cytoplasm. At this time point, minimal epidermal hyperplasia was evident in wild-type epidermis but not knockout epidermis. At $48 \mathrm{~h}$ following exposure, there was loss of keratinocytes, as evidenced by thinning of the epidermis in both wild-type and knockout epidermis. Changes in the skin of wild-type mice were similar at 72 and $96 \mathrm{~h}$ post-exposure. At these time points, there was considerable heterogeneity in lesions in each mouse, with ulceration in some areas and moderate to marked epidermal hyperplasia in other areas. Skin from knockout mice did not display similar areas of epidermal ulceration; instead, lesions consisted only of minimal to mild epidermal hyperplasia throughout the epidermis. One week following UVR exposure, there was marked re-epithelialization and epidermal hyperplasia in wild-type mice, whereas only mild to moderate epidermal hyperplasia was observed in knockout epidermis.

\section{DNA Damage}

Despite the difference in cutaneous response to UVR, immunohistochemical staining for CPDs at 12 and $24 \mathrm{~h}$ post-exposure indicated that both wild-type and knockout epidermis had sustained considerable DNA damage (Figure 3). These results suggest that it was not the induction or repair of DNA damage that differed between the genotypes, instead it was the response to similar levels of damage that was dissimilar.

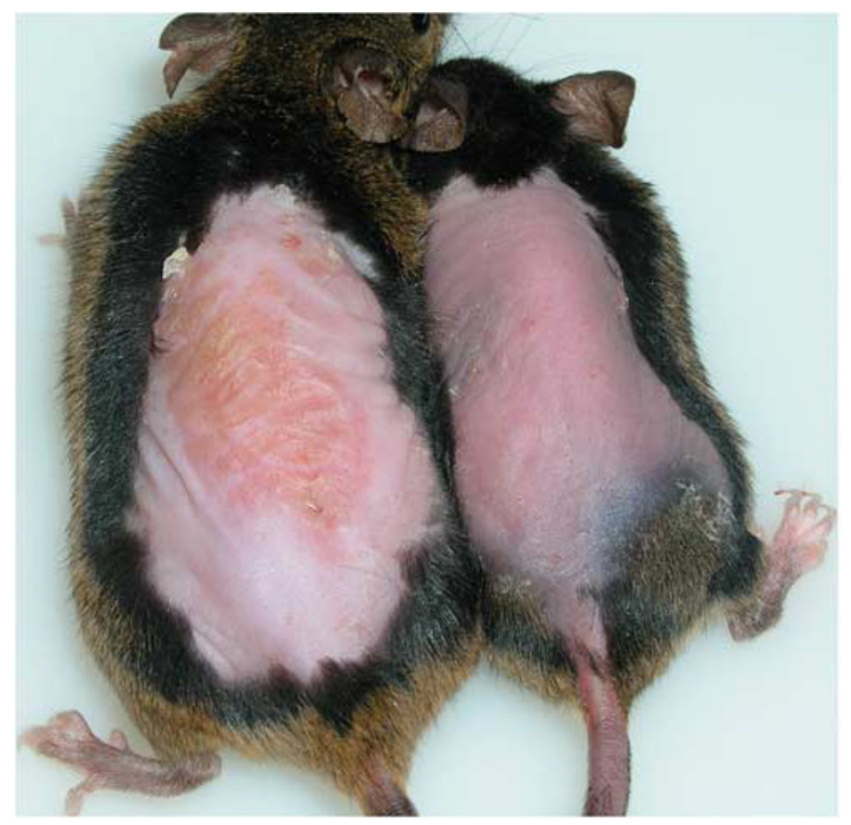

Figure 1 Representative image of the gross appearance of skin $96 \mathrm{~h}$ after exposure to 3 MED of UVR. The wild-type mouse on the left has extensive erythema and dermal edema, as well as scaling and peeling of the skin, whereas there is only mild cutaneous erythema in the knockout mouse on the right.

\section{Skin Thickness}

UVR-induced dermal edema was evaluated by measuring skin thickness. As the unexposed skin of the Slug-knockout mice was significantly thinner than that of the wild-type mice ( $0.82 \pm 0.31$ vs $1.03 \pm 0.12 \mathrm{~mm}, P=0.021)$, skin thickness was compared as the percent change compared to unexposed skin. In all mice, skin thickness increased in response to UVR at time points more than $24 \mathrm{~h}$ after exposure. Knockout mice had consistently less thickening than wild-type mice at all time points, and this difference was statistically significant at early (12 and $24 \mathrm{~h}$ ) and late (96h and 1 week) time points (Figure 4).

Histologically, the unexposed epidermis of the knockout mice was significantly thinner that that of the wild-type mice, as measured from hematoxylin- and eosin-stained sections (7.38 \pm 0.99 vs $8.91 \pm 1.67 \mu \mathrm{m}, P=0.016)$. Based on histopathology findings, the early changes in skin thickness following UVR appeared to represent inflammation-associated edema, whereas later changes reflected the loss of skin flexibility due to epidermal necrosis and hyperkeratosis. At 1 week after UVR exposure, the difference in skin thickness may also have reflected epidermal hyperplasia, which was much more prominent in wild-type than Slug-knockout skin. We verified hyperplasia by demonstrating significantly increased numbers of epidermal cells per unit area in wildtype compared to Slug-knockout skin at 1 week after exposure (Figure 4). However, Ki-67 staining revealed few differences between wild-type and Slug-knockout epidermis either before or at most time points following UVR exposure 

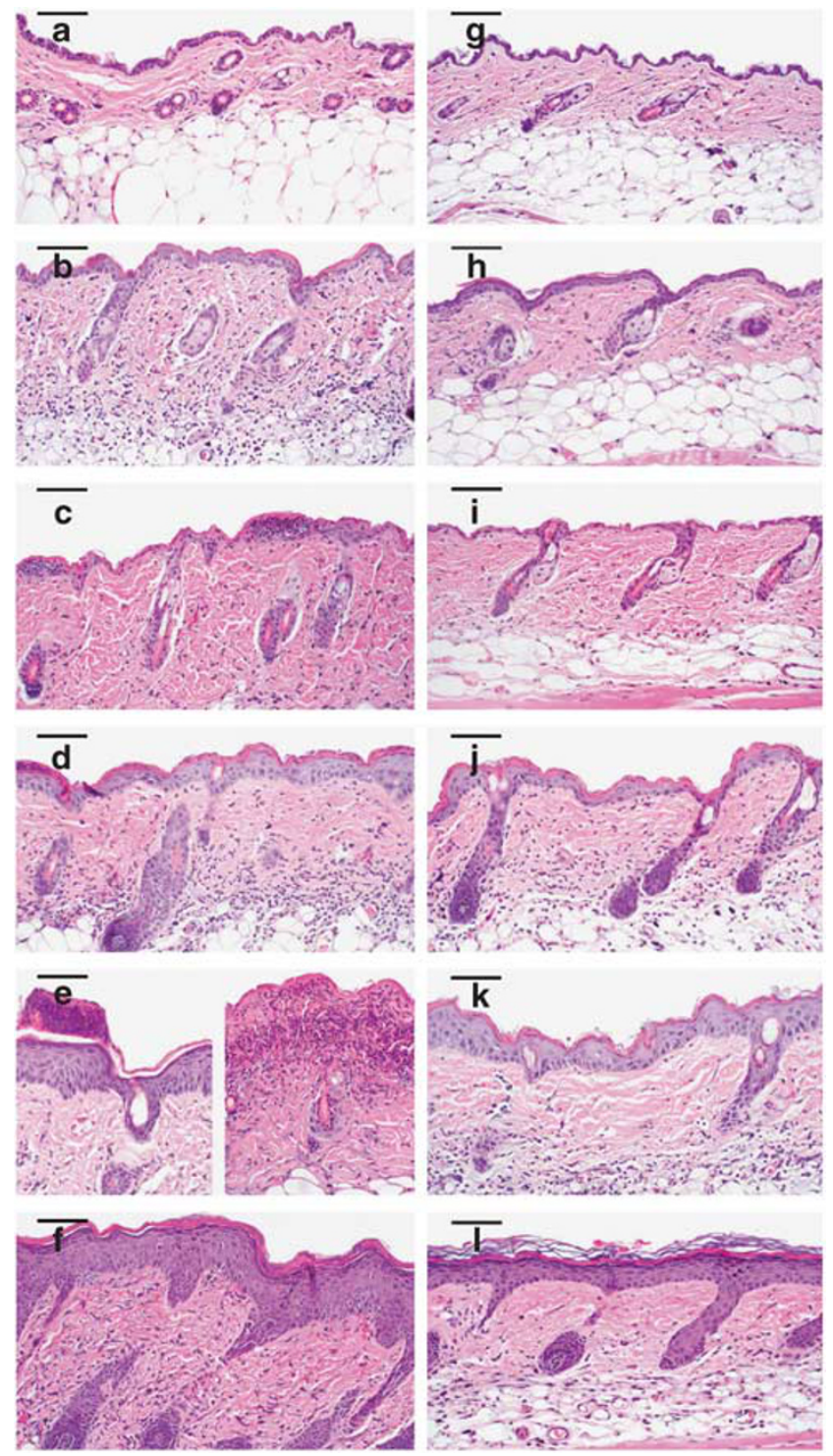

Figure 2 Histologic appearance of the skin following exposure to 3 MED of UVR. Wild-type skin (a-f): unexposed skin (a). By $24 \mathrm{~h}$ post-UVR, there are marked neutrophil infiltrates (b). At $48 \mathrm{~h}$, there is widespread apoptosis of epidermal keratinocytes (c). Seventy-two hours following UVR, there is moderate epidermal hyperplasia (d). At $96 \mathrm{~h}$ following UVR exposure, lesions vary from moderate or marked epidermal hyperplasia (e, left panel) to complete loss of the epidermis (e, right panel). By 1-week post-exposure, there is marked epidermal hyperplasia (f). Slug-knockout skin ( $(\mathbf{g}-\mathbf{I})$ : unexposed skin $(\mathbf{g})$. There are minimal neutrophil infiltrates at $24 \mathrm{~h}(\mathbf{h})$ following UVR exposure. By $48 \mathrm{~h}$, there is almost complete apoptosis of keratinocytes (i). Epidermal hyperplasia increases from $72 \mathrm{~h} \mathrm{(j)}$ to $96 \mathrm{~h} \mathrm{(k)}$ and 1 week (I) post-exposure. In contrast to wild-type skin, widespread necrosis does not occur at $96 \mathrm{~h}$ following UVR and epidermal hyperplasia is more modest. Hematoxylin and eosin staining. Bar $(\mathbf{a}-\mathbf{I})=100 \mu \mathrm{m}$.

(Figure 5). At $72 \mathrm{~h}$ post-exposure, there were moderately but significantly reduced numbers of Ki-67-positive keratinocytes in knockout skin; at 1-week post-exposure, the number of Ki-67-positive keratinocytes was significantly greater in knockout than that in wild-type epidermis. Thus, any decrease in epidermal proliferation in the knockout mice seen in the first few days after UVR exposure was apparently being compensated for by 1 week after exposure. These findings are consistent with our previous report of delayed expression of keratin 6, a marker of epidermal hyperplasia, in the skin of Slug-knockout $v s$ wild-type mice exposed to UVR. ${ }^{3}$

\section{Inflammation}

Evaluation of the acute inflammatory response to UVR in these mice included quantitation of the numbers of neutrophils, mast cells, and CD3-positive cells, as well as evaluation of MPO activity and COX-2 mRNA expression. UVR stimulated an influx of neutrophils into the dermis in both genotypes. In the wild-type mice, this infiltrate was pronounced and persistent; however, in the knockout skin, there were consistently fewer neutrophils in the dermis at all time points (Figure 6). The difference between dermal neutrophil numbers in the two genotypes was significant at $12,24,48$, and $72 \mathrm{~h}$ post-UVR. MPO activity, an indicator of neutrophil activation, was also enhanced after UVR exposure, with values in wild-type mice significantly higher than those in Slug-knockout mice at 12, 72, and $96 \mathrm{~h}$ and 1 week after UVR exposure (Figure 6).

Significantly increased numbers of mast cells were noted in the unexposed skin of Slug-knockout mice (13.02 \pm 4.35 dermal mast cells per $\times 400$ field) compared to wild-type mice $(9.17 \pm 3.21$ dermal mast cells per $\times 400$ field) (Figure 7). At $12 \mathrm{~h}$ post-exposure, the difference in mast cell numbers between the two genotypes was not significant, but at $24 \mathrm{~h}$ following UVR exposure, there were significantly more mast cells in the knockout skin $(11.26 \pm 3.99$ dermal mast cells per $\times 400$ field) compared to the wild-type skin $(7.69 \pm 3.12$ dermal mast cells per $\times 400$ field). Mast cells are resident immune cells in the dermis and have an important role in mediating UVR-induced inflammation. ${ }^{6}$ In the present instance, differences in mast cell numbers did not appear to account for differences between wild-type and knockout mice in the UVR-induced cutaneous inflammatory response. However, although we saw few differences between the genotypes in dermal mast cell numbers, our study did not compare the functional capabilities of the mast cells, which may differ between the two genotypes.

In a previous microarray study, we found that expression of mRNA encoding the $\zeta$-chain of the $\mathrm{CD} 3$ receptor was decreased 1.7-fold in untreated Slug-knockout epidermis compared to wild-type epidermis. ${ }^{5}$ In keeping with these findings, immunohistochemical staining for $\mathrm{CD} 3$ in the present study revealed decreased numbers of $T$ cells in the unexposed epidermis of Slug-knockout mice $(3.77 \pm 2.16 \mathrm{vs}$ $4.7 \pm 0.86$ in the wild type); however, this difference was not significant. Our microarray study also demonstrated reduced expression of both the $\gamma$ - and $\delta$-chains of the T-cell receptor in untreated Slug-knockout epidermis, suggesting that there were fewer $\gamma-\delta$ T cells in the knockout than in the wild-type epidermis. ${ }^{5}$ In the present study, a progressive decrease in the 

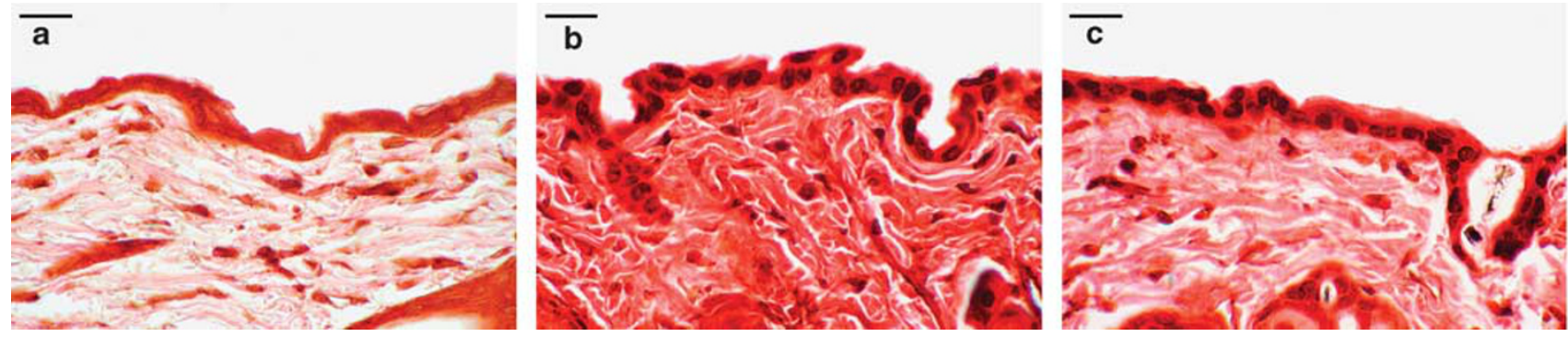

Figure 3 Immunohistochemical detection of CPDs following exposure to 3 MED of UVR. (a) Unexposed skin of a wild-type mouse lacks staining for CPDs. The unexposed skin of knockout mice also lacked positive nuclear staining for CPDs. (b, c) Both the wild-type and knockout mice have abundant positive nuclear staining for CPDs. Bar (a-c) $=20 \mu \mathrm{m}$.
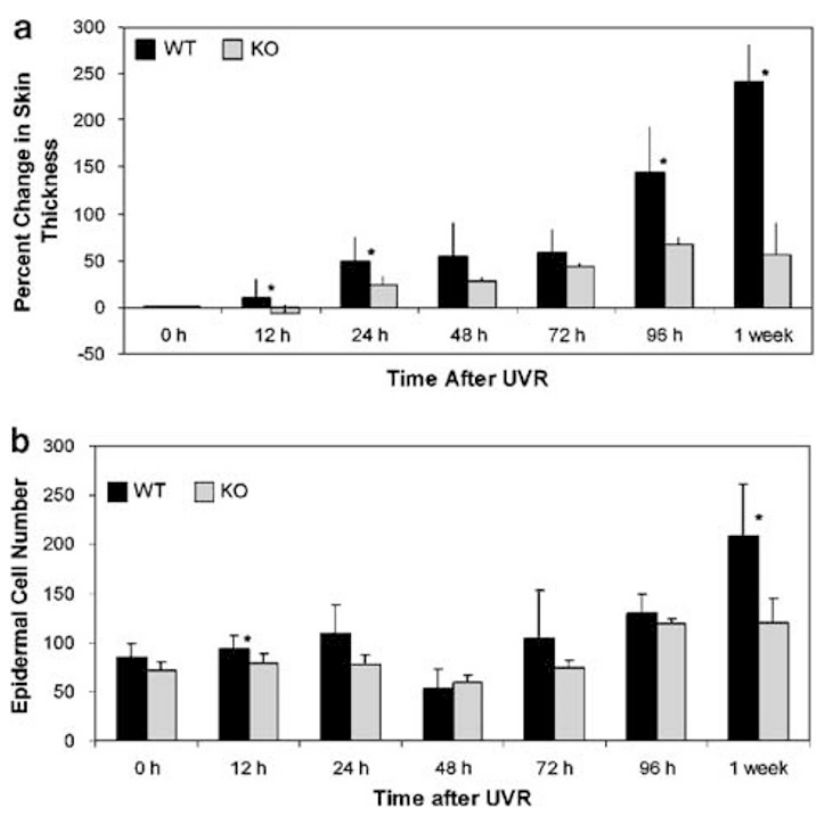

Figure 4 Changes in skin and epithelial thickness following exposure to 3 MED of UVR. (a) Skin thickness as measured with digital calipers. Data represent the percent change in skin thickness relative to pre-UVR skin thickness. Skin thickness is consistently less in the Slug-knockout mice compared to wild-type mice. (b) Skin thickness as measured by counting the number of epidermal cells in six hematoxylin- and eosin-stained $\times 400$ fields. There is a decreased proliferative response in the Slug-knockout mice at $12 \mathrm{~h}$ and 1 week following UVR exposure. ${ }^{\star} P<0.05$. Error bars represent the standard deviation.

number of intraepidermal, CD3-positive $\mathrm{T}$ cells occurred from 12 to $48 \mathrm{~h}$ post-exposure in wild-type skin, relative to the unexposed epidermis (Figure 8). A similar trend was not seen in the skin of knockout mice. As a result, the number of intraepidermal $\mathrm{T}$ cells in Slug-knockout mice was significantly higher than that in wild-type mice at the 24 and $48 \mathrm{~h}$ time points.

To further evaluate the inflammatory response in the wildtype and knockout mice following a single UVR exposure, we compared COX-2 mRNA expression by quantitative RT-PCR (Figure 9). UVR induction of COX-2 mRNA has been previously reported in the skin of mice, based on microarray analysis. ${ }^{10}$ COX-2 induction results in the production of prostaglandins that modulate diverse aspects of inflammation, including vascular permeability, fever, and blood flow. ${ }^{11}$ COX-2 has previously been shown to increase Snail expression, ${ }^{12}$ and Snail has been shown to repress the transcription of prostaglandin dehydrogenase, the enzyme which inactivates the major effector of COX-2 activity, prostaglandin E2. ${ }^{13}$ There was no difference between Slug-knockout and wild-type epidermis in COX-2 mRNA expression either before or at 12, 24, 48, or $72 \mathrm{~h}$ following UVR exposure. At $96 \mathrm{~h}$ after UVR exposure, there was a significant difference between the genotypes in COX-2 expression, with a second peak of COX-2 expression in wild-type epidermis that was lacking in Slug-knockout epidermis. This second peak of COX-2 expression likely corresponded to the ulceration seen in wild-type mice at this time point.

Differences in the number or permeability of blood vessels in the dermis may have accounted for differences in the cutaneous inflammatory response to UVR between knockout and wild-type skin. However, staining for CD31 did not reveal significant differences in the number or average diameter of dermal blood vessels in unexposed skin of wild-type mice $(3.32 \pm 1.02$ vessels per six $\times 400$ fields of dermis; $5.94 \pm 1.38 \mu \mathrm{m}$ diameter) $v s$ knockout mice $(4.79 \pm 1.06$ vessels per six $\times 400$ fields of dermis; $6.875 \pm 2.19 \mu \mathrm{m}$ diameter). Because differences between wild-type and knockout skin were apparent so soon after UVR exposure, it is unlikely that changes in vessel number could have been responsible for differences in inflammatory response.

\section{Expression of Inflammatory Mediators}

As cytokines produced in the epidermis are major mediators of the acute inflammatory response, focused cytokine array analysis was performed to help explain the differences in cutaneous inflammation seen between the wild-type and knockout mice following acute UVR exposure. Expression of inflammatory genes in the two genotypes was evaluated at 12 and $24 \mathrm{~h}$ following UVR exposure. Of the 112 genes represented on the array of inflammatory mediators, only 10 were found to be consistently expressed in at least one of the four experimental groups (Table 1). 


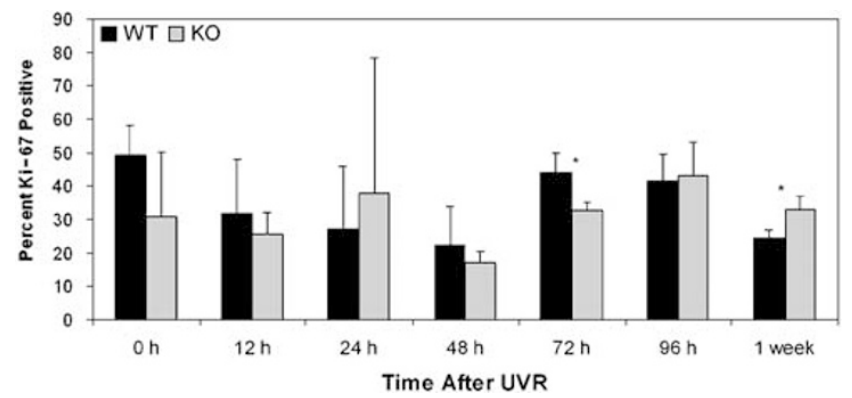

Figure 5 Immunohistochemical detection of Ki-67-positive cells in the epidermis following exposure to 3 MED of UVR. The percent of Ki-67positive cells in the epidermis was determined in each of six $\times 400$ fields for each mouse. Numbers of Ki-67-positive cells progressively decrease in the wild-type mice following a single UVR exposure; this decrease is not seen in the knockout mice. At $72 \mathrm{~h}$ post-exposure, there are significantly more Ki67-positive cells in the wild-type than those in the knockout epidermis. At 1 week post-exposure, there are significantly more Ki-67-positive cells in the knockout than those in the wild-type epidermis. ${ }^{\star} P<0.05$. Error bars represent the standard deviation.
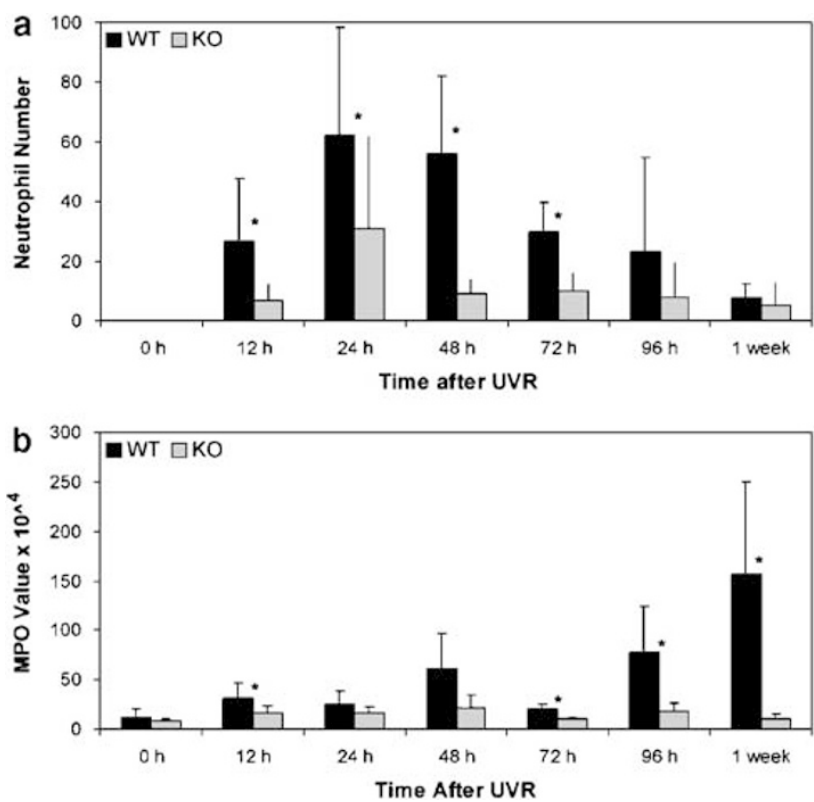

Figure 6 Neutrophil infiltrates in the dermis following exposure to 3 MED of UVR. (a) The average number of neutrophils present in the dermis, as determined by counting the number of neutrophils in six hematoxylin- and eosin-stained $\times 400$ fields. Neutrophil infiltrates peak in both the wild-type and Slug-knockout mice at $24 \mathrm{~h}$ post-UVR exposure, but are markedly decreased in the Slug-null compared to wild-type mice. (b) MPO activity demonstrates decreased neutrophil activation in the Slug-knockout skin. ${ }^{\star} P<0.05$. Error bars represent the standard deviation.

Complement component 3, high-affinity IgG Fc receptor I, and interleukin-12 $\beta$ (IL12b) were expressed at all time points in both wild-type and Slug-knockout skin; no significant differences were seen between the two genotypes at the same time points or between the two time points in either genotype. Thus, these genes did not appear to be UVR inducible over the time course of these studies, nor did differences in their expression account for differences in the UVR-induced cutaneous inflammatory response of wild-type and Slug-knockout mice.

A number of genes were expressed by UVR-exposed wild-type epidermis but were not expressed by similarly treated Slug-knockout epidermis. These included the proinflammatory chemokines and cytokines fractalkine (Cx3cl1), Cxcl2, interleukin-1 $\beta$ (IL1b), and macrophage migration inhibitory factor (Mif). Differences between wild-type and Slug-knockout skin in UVR inducibility of these mediators, all of which are known to play a role in leukocyte chemotaxis, ${ }^{14-16}$ might well have accounted for differences in inflammatory cell infiltrate in the UVR-exposed skin of the two genotypes. Moreover, the interleukin12 p35 subunit (IL12a) was expressed at both time points following UVR in wild-type epidermis but not in Slugknockout epidermis. IL12 is believed to block UVR-induced immunosuppression. ${ }^{17}$ Interestingly, the interleukin-1 decoy receptor (IL1r2), which functions to negatively regulate IL1 activity, ${ }^{18}$ was also induced in wild-type skin by UVR. Another negative regulator of IL1 activity, IL1r antagonist, has previously been shown to be induced by UVR in keratinocytes. ${ }^{19}$ A component of the high-affinity IgE Fc receptor was expressed in wild-type epidermis $24 \mathrm{~h}$ after UVR exposure, but was not expressed in wild-type epidermis at $12 \mathrm{~h}$ after exposure or in Slug-knockout skin at either time point following UVR exposure. The significance of this finding is unclear. Although both keratinocytes and Langerhans cells may express the low-affinity receptor for IgE ( $\mathrm{Fc}$ epsilon RII), ${ }^{20,21}$ neither has been reported to express the high-affinity receptor.

\section{Apoptosis}

P53-dependent keratinocyte apoptosis is a prominent feature of sunburn ${ }^{22}$ and can be responsible for the release of proinflammatory substances. ${ }^{23,24}$ Slug is reported to have antiapoptotic effects; ${ }^{25,26}$ however, the relationship between Slug and p53 is complex. We show here that there was no difference in basal expression of p53 protein between untreated wild-type and Slug-knockout epidermis. There was a dramatic increase in p53 protein expression at times up to $96 \mathrm{~h}$ post-UVR in both wild-type and knockout mice (Figure 10), but there was no difference between the genotypes in the numbers of p53-positive epidermal cells at any time point. As expected, numbers of cleaved caspase 3-positive cells reflected the numbers of p53-positive cells (Figure 10) and were associated with morphologic evidence of apoptosis. ${ }^{22} \mathrm{~A}$ significant difference in numbers of cleaved caspase 3-positive cells between wild-type and Slug-knockout epidermis was seen only at $12 \mathrm{~h}$ after UVR exposure $(7.21 \pm 6.58 \mathrm{vs}$ $1.27 \pm 0.98)$, suggesting a somewhat delayed apoptotic response in Slug epidermis. 


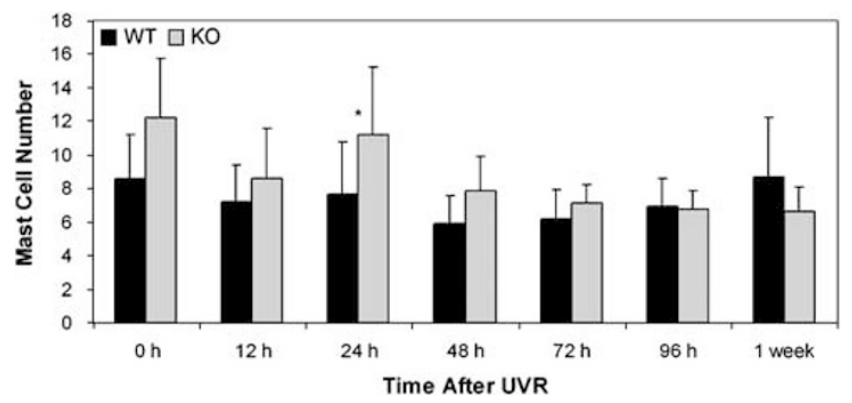

Figure 7 Mast cell counts in the dermis following exposure to 3 MED of UVR. The average number of mast cells in each of six acid-fast-stained $\times 400$ fields was determined for each mouse. These findings demonstrate significantly more mast cells in the dermis of Slug-knockout compared to wild-type mice at $24 \mathrm{~h}$ post-UVR. ${ }^{*} P<0.05$. Error bars represent the standard deviation.

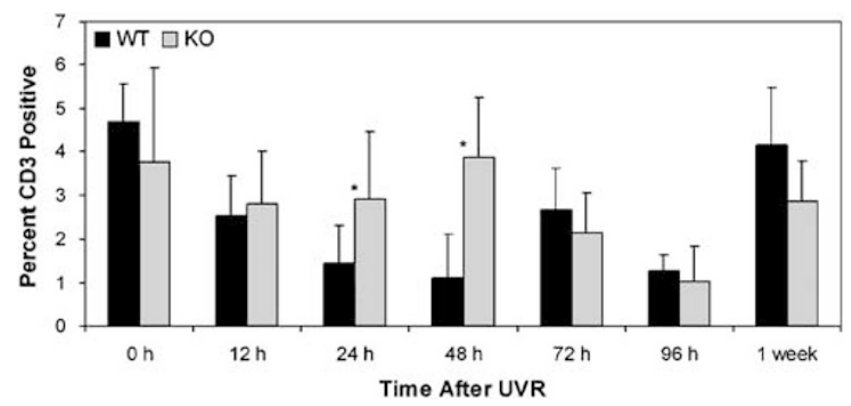

Figure 8 Immunohistochemical detection of CD3-positive cells in the epidermis following exposure to 3 MED of UVR. The percent of CD3-positive cells in the epidermis was determined in each of six $\times 400$ fields for each mouse. Numbers of CD3-positive cells progressively decrease in the wildtype mice following a single UVR exposure; this decrease is not seen in the knockout mice. At 24 and $48 \mathrm{~h}$ post-exposure, there are significantly more CD3-positive cells in the knockout than in the wild-type epidermis. ${ }^{\star} P<0.05$. Error bars represent the standard deviation.

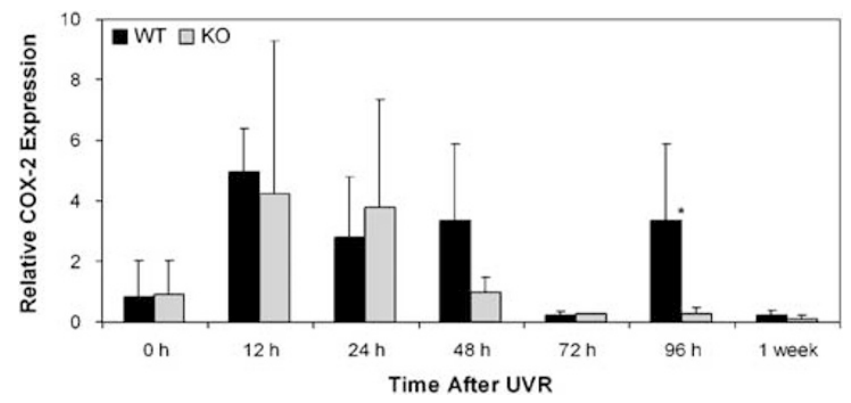

Figure 9 Quantitative RT-PCR detection of COX-2 mRNA in UVR-exposed epidermis. By $12 \mathrm{~h}$ post-UVR, COX-2 expression has increased dramatically in both the wild-type and Slug-knockout mice; however, at $96 \mathrm{~h}$, there is significantly more COX-2 expression in the wild-type mice than in the Slugknockout mice. COX-2 expression values are normalized to GAPDH expression. ${ }^{\star} P<0.05$. Error bars represent the standard deviation.

\section{DISCUSSION}

The acute response to UVR in 129 wild-type mice in this study was first evidenced by increased p53 protein expression and COX-2 mRNA expression at 12 and $24 \mathrm{~h}$ after exposure.
Peak cleaved caspase 3 expression was observed at $48 \mathrm{~h}$, the onset of ulceration occurred after $72 \mathrm{~h}$, and ulceration was followed by epidermal hyperplasia. Dermal edema and inflammatory cell infiltrates were prominent by $24 \mathrm{~h}$ postexposure. Slug-knockout mice exhibited markedly attenuated inflammatory responses to UVR. Knockout mice had decreased dermal edema, neutrophil infiltration, and COX-2 expression, as well as altered cytokine profiles and proliferative responses compared to wild-type mice. Having previously reported UVR induction of Slug in the murine epidermis, we now suggest that the complex inflammatory response of the skin following UVR is regulated, at least in part, by Slug.

We observed significantly more dermal mast cells in the Slug-knockout mice than in the wild-type mice at $24 \mathrm{~h}$ following a single dose of UVR. Given the critical importance of mast cells in the cutaneous inflammatory response, it was surprising to see increased mast cell numbers in the presence of reduced inflammation in the knockout mice. Following UVR exposure of the skin, mast cells are thought to release histamine which, in turn, leads to the production of prostaglandins and other inflammatory mediators. ${ }^{6}$ We are currently characterizing mast cells from Slug-knockout mice to determine if they exhibit impaired functional capabilities. Significantly increased numbers of epidermal CD3-positive cells were also detected in the Slug-null mice compared to wild-type mice; however, this finding appeared to reflect reduced UVR-induced depletion of intraepidermal lymphocytes rather than enhanced recruitment of CD3-positive cells to the epidermis.

Given the obvious relationship between cytokines and chemokines and the inflammatory response, inflammatory mediator expression profiles were examined in the mice following UVR exposure. Several of the cytokines and chemokines identified as differing in expression between UVR-exposed wild-type and Slug-knockout epidermis in the present study have previously been shown to be produced by keratinocytes and to be induced following UVR exposure of the skin, including IL1b, ${ }^{10,27,28}$ IL12, $^{29} \mathrm{Cxcl} 2,{ }^{10}$ and Mif. ${ }^{16}$ Induction of IL1b expression has been reported following UVR exposure of CD1 mice ${ }^{10}$ and BALB/c mice ${ }^{27,28}$ and is proposed to be the initiating event in the inflammatory response to UVR. ${ }^{27}$ Several of the mediators induced by UVR in wild-type but not knockout epidermis play important roles in recruiting inflammatory cells to UVR-exposed skin. Decreased production of the potent neutrophil chemoattractants IL1b and Cxcl2 in the UVR-exposed Slug-knockout epidermis may underlie the diminished neutrophil response seen in these mice. ${ }^{15}$ Examination of the 1000 bases upstream from the transcription start sites in the IL1b, IL1r2, IL12a, Mif, $\mathrm{Cxcl} 2$, and $\mathrm{Cx} 3 \mathrm{cl} 1$ revealed that single canonical Slug binding sites (CACCTG or CAGGTG) ${ }^{30}$ were present in the promoters of IL12a, Mif, $\mathrm{Cxcl} 2$, and $\mathrm{Cx} 3 \mathrm{cl} 1$ but absent from the promoters of IL1b and IL1r2. Thus, Slug regulation of these latter two genes must be indirect. 
Table 1 Comparative gene expression following UVR exposure

\begin{tabular}{|c|c|c|c|c|c|c|c|c|}
\hline & \multicolumn{2}{|c|}{$12 \mathrm{~h}, \mathrm{KO}$} & \multicolumn{2}{|c|}{$24 \mathrm{~h}, \mathrm{KO}$} & \multicolumn{2}{|c|}{$12 \mathrm{~h}, \mathrm{WT}$} & \multicolumn{2}{|c|}{$24 \mathrm{~h}, \mathrm{WT}$} \\
\hline & Mean & s.d. & Mean & s.d. & Mean & s.d. & Mean & s.d. \\
\hline$x 3 \mathrm{cl} 1$ & Absent & - & Absent & - & Absent & - & 0.533 & 0.43 \\
\hline $\mathrm{CxCl} 2$ & Absent & - & Absent & - & Absent & - & 0.582 & 0.09 \\
\hline cer1g & Absent & - & Absent & - & Absent & - & 0.507 & 0.04 \\
\hline L1b & Absent & - & Absent & - & Absent & - & 0.723 & 0.24 \\
\hline L1r2 & Absent & - & Absent & - & Absent & - & 0.511 & 0.12 \\
\hline Mif & Absent & - & Absent & - & Absent & - & 0.732 & 0.15 \\
\hline $\operatorname{IL} 12 \mathrm{a}^{\mathrm{a}}$ & Absent & - & Absent & - & 0.664 & 0.166 & 0.641 & 0.085 \\
\hline$C 3^{b}$ & 0.572 & 0.219 & 0.747 & 0.411 & 0.586 & 0.027 & 0.576 & 0.398 \\
\hline $\mathrm{Fcgr}^{\mathrm{b}}$ & 0.985 & 0.794 & 1.694 & 1.293 & 0.865 & 0.460 & 0.869 & 0.65 \\
\hline IL $12 b^{b}$ & 1.008 & 0.707 & 1.274 & 0.766 & 1.041 & 0.182 & 0.864 & 0.615 \\
\hline GAPDH & 1.000 & 0.000 & 1.000 & 0.000 & 1.000 & 0.000 & 1.000 & 0.000 \\
\hline
\end{tabular}

Each value represents the average of three replicates. Each replicate represents pooled RNA from two mice.

${ }^{\mathrm{a}}$ No significant change over time in WT.

${ }^{\mathrm{b}}$ No significant difference between $\mathrm{KO}$ and $\mathrm{WT}$; no significant change over time in either KO or WT.
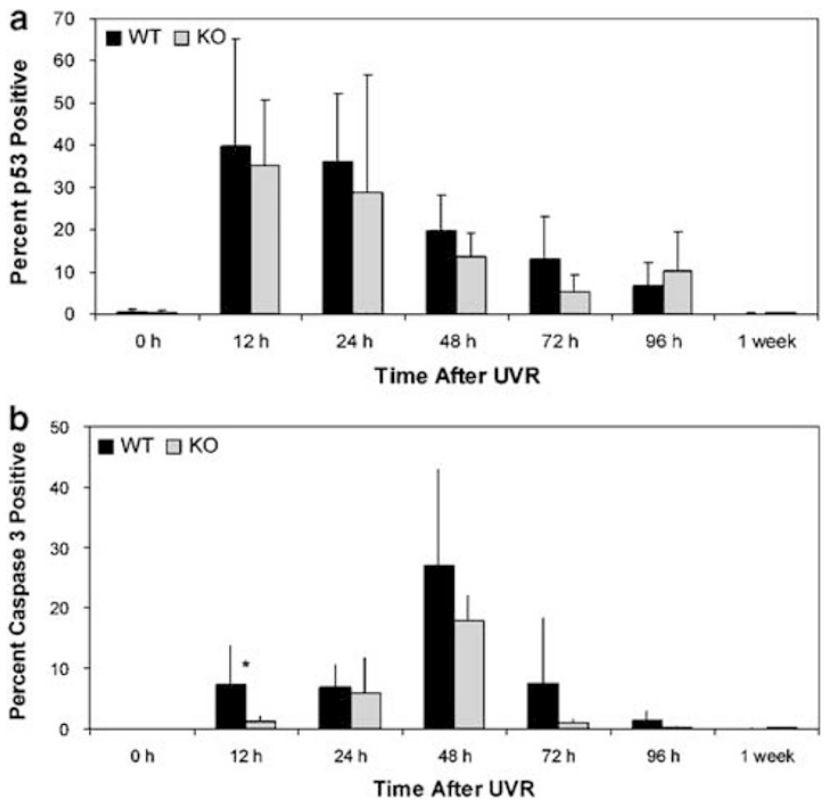

Figure 10 Apoptosis in the epidermis following exposure to 3 MED of UVR. (a) Immunohistochemical detection of p53. Expression of p53 increases dramatically following UVR exposure and then progressively declines. No significant differences in expression are observed between the wild-type and Slug-knockout mice. (b) Immunohistochemical detection of cleaved caspase 3 . Cleaved caspase 3 immunoreactivity highlights apoptotic cells and is significantly decreased in the Slug-knockout mice at $12 \mathrm{~h}$ post-UVR exposure compared to wild-type mice. In both Slug-knockout and wildtype mice, cleaved caspase 3 immunoreactivity peaks at $48 \mathrm{~h}$ following UVR exposure. For both p53 and cleaved caspase 3 , the percent of positive cells in the epidermis was determined in each of six $\times 400$ fields for each mouse. ${ }^{*} P<0.05$. Error bars represent the standard deviation.
Caspase 3 is an effector caspase that mediates many of the cellular events that result in apoptosis. ${ }^{31}$ In this study, immunohistochemical detection of cleaved caspase 3 was used to identify apoptotic keratinocytes. This revealed a significant decrease in UVR-induced apoptosis in the Slug-null epidermis compared to wild-type epidermis $12 \mathrm{~h}$ following UVR exposure. Slug is believed to have antiapoptotic functions, as evidenced by increased numbers of apoptotic cells in the bone marrow of Slug-knockout mice relative to their wildtype counterparts following $\gamma$-irradiation. ${ }^{26}$ Our observation was thus surprising and warrants further investigation. At later time points, however, there was no difference in cleaved caspase 3 immunoreactivity, suggesting that the absence of Slug may only delay and not prevent the onset of UVRinduced apoptosis.

UVR-induced apoptosis is p53-dependent, ${ }^{32}$ but is also modulated by reactive oxygen species, triggering of cell-death receptors, autocrine release of death ligands, and mitochondrial damage with subsequent cytochrome $c$ release. ${ }^{24}$ The relationship between Slug and p53 remains unclear. One study found that the absence of Slug did not affect p53 protein induction following UVR exposure. ${ }^{24}$ There is a Slug binding site in the p53 promoter region, and overexpression of Slug or Snail using an adenoviral vector in human breast carcinoma cells lines (MCF7) results in a modest decrease in p53 mRNA and protein expression and prevents apoptosis induced by the DNA-damaging agent adriamycin. ${ }^{25}$ It is postulated that the induction of $\mathrm{p} 53$ by $\gamma$-irradiation results in increased expression of Slug, which then represses transcription of the proapoptotic protein, Puma. ${ }^{33,34}$ Expression of Slug, therefore, decreases Puma expression, resulting in a net antiapoptotic effect. ${ }^{34}$ In the absence of Slug, however, the proapoptotic Puma is expressed. ${ }^{34}$ In contrast, another study found no change in DNA damage-induced p53 expression in normal hematopoietic stem cells from Slugknockout mice. ${ }^{25}$ The interactions between $\mathrm{p} 53$ and Slug may be dependent upon the cell type or the type of DNA damage that induced p53 expression. ${ }^{25}$

We have previously reported delayed expression of keratin 6 in the epidermis of the Slug-knockout mice relative to the wild-type mice. ${ }^{3}$ Because keratin 6 is a marker of proliferation, ${ }^{35}$ these results suggested a delayed proliferative response in Slug-knockout epidermis following UVR exposure. Decreased keratinocyte proliferation in the absence of Slug was suggested in the current study by finding significantly decreased numbers of epidermal cells at 1 week post-UVR in the knockout mice, a time at which wild-type epidermis exhibited a robust proliferative response. However, Ki-67 staining suggested little overall difference in cell proliferation between wild-type and knockout skin. There were fewer Ki-67-positive cells in knockout keratinocytes at $72 \mathrm{~h}$ postexposure, but by 1 week after exposure Slug-knockout skin had more Ki-67-positive cells than wild-type skin. The role of Slug and Snail in cell proliferation has previously been demonstrated by microarray analysis of MDCK cells that 
overexpressed Slug or Snail. Cells expressing high levels of these Snail family members had altered expression of various growth factors (hepatoma-derived growth factor, fibroblast growth factor-13, fibroblast growth factor-19, and cyclin D1) and cyclin-dependent kinase inhibitors (p21Cip and p18). ${ }^{36}$ Similarly, our microarray study comparing untreated epidermis of wild-type and Slug-null mice identified decreased expression of cyclins D2 and G2, which regulate cell cycle progression. ${ }^{5}$ These findings are in contrast to a previous study that showed decreased keratinocyte proliferation without changes in cyclin D expression in response to enhanced Slug expression. ${ }^{37}$ Another study found no change in proliferation as measured by bromodeoxyuridine incorporation in human keratinocytes transfected with a Slug expression vector. ${ }^{2}$ Increased Slug expression has also been shown to reduce proliferation of cultured keratinocytes. ${ }^{37,38}$ Thus, the role of Slug in epidermal proliferation remains obscure, and our present results do not clarify the situation.

Slug is a novel and unexpected participant in the acute inflammatory response of the skin to UVR. Wild-type levels of Slug expression appear to be required for maximal levels of neutrophil influx, keratinocyte necrosis, and epidermal hyperplasia in UVR-exposed skin. At present, the precise step of the inflammatory pathway at which Slug exerts its effect is not known. The defect in the cutaneous inflammatory response of Slug-knockout mice to UVR may lie in the failure of keratinocytes to release appropriate proinflammatory mediators or in the inability of leukocytes to response appropriately to these signals. A number of considerations suggest that the keratinocyte is the cell responsible for the abnormal response. Slug is expressed in adult keratinocytes but not in adult leukocytes. ${ }^{4}$ Moreover, UVR exposure of the skin rapidly induces enhanced Slug expression in keratinocytes. ${ }^{3}$ Most of the UVB striking the skin is absorbed by the epidermis, and only UVA penetrates to the dermis to reach blood vessels and leukocytes: ${ }^{39,40}$ it is the UVB that accounts for much of the inflammatory response of the skin to UVR. $^{32,41}$ The present studies show that UVR exposure induces expression of a variety of proinflammatory epidermal cytokines and chemokines in wild-type skin that fail to be induced in the epidermis of Slug-knockout mice. In the absence of these mediators of inflammation, it is likely that the inflammatory response of the skin and the changes attendant upon this response are lacking in Slug-knockout skin. However, our studies do not exclude the possibility that the response of Slug-knockout leukocytes to proinflammatory signals is also altered. Studies investigating the function and responsiveness of Slug-knockout leukocytes are underway. In particular, we plan to test the cutaneous inflammatory response of lethally irradiated wild-type mice reconstituted with Slug-knockout hematopoietic cells, as well as the reciprocal chimeras.

Based on our findings to date, further evaluation of the cutaneous inflammatory response to non-UVR inflammatory stimuli in Slug-knockout mice seems warranted. Ad- ditionally, the role of Slug in DNA repair and evaluation of DNA repair mechanisms following UVR exposure in Slugknockout mice should be investigated. Future studies will provide insight into the role of this new and potentially important factor in the acute inflammatory response. Ultimately, modulating Slug activity may be a way to manipulate the cutaneous inflammatory response and reduce its detrimental effects, including acute tissue damage and tumor promotion.

\section{ACKNOWLEDGEMENT}

This work was supported by National Institutes of Health R01 CA089216 and Ruth L Kirschstein National Research Service Award (T32 Institutional National Research Service Award in Mouse Models of Human Disease).

\section{DISCLOSURE/DUALITY OF INTEREST}

None.

1. Carver EA, Jiang $R$, Lan $Y$, et al. The mouse snail gene encodes a key regulator of the epithelial-mesenchymal transition. Mol Cell Biol 2001;21:8184-8188.

2. Savagner $P$, Kusewitt DF, Carver EA, et al. Developmental transcription factor slug is required for effective re-epithelialization by adult keratinocytes. J Cell Physiol 2005;202:858-866.

3. Hudson LG, Choi C, Newkirk KM, et al. Ultraviolet radiation stimulates expression of snail family transcription factors in keratinocytes. Mol Carcinog 2007:46:257-268.

4. Parent $A E$, Choi $C$, Caudy $K$, et al. The developmental transcription factor Slug is widely expressed in tissues of adult mice. J Histochem Cytochem 2004;52:959-965.

5. Newkirk KM, MacKenzie DA, Bakaletz AP, et al. Microarray analysis demonstrates a role for Slug in epidermal homeostasis. J Invest Dermatol 2008;128:361-369.

6. Clydesdale GJ, Dandie GW, Muller HK. Ultraviolet light induced injury: immunological and inflammatory effects. Immunol Cell Biol 2001;79:547-568.

7. Jiang R, Lan $Y$, Norton $C R$, et al. The Slug gene is not essential for mesoderm or neural crest development in mice. Dev Biol 1998;198:277-285.

8. Sheehan DC, Hrapchak BB. Theory and Practice of Histotechnology, 2nd edn. Battelle Press: Ohio, 1980, pp 235-237.

9. Ramakers C, Ruijter JM, Deprez RH, et al. Assumption-free analysis of quantitative real-time polymerase chain reaction (PCR) data. Neurosci Lett 2003;339:62-66.

10. Madson JG, Lynch DT, Tinkum KL, et al. Erbb2 regulates inflammation and proliferation in the skin after ultraviolet irradiation. Am J Pathol 2006;169:1402-1414.

11. Lee $\mathrm{J}$, Mukhtar H, Bickers DR, et al. Cyclooxygenases in the skin: pharmacological and toxicological implications. Toxicol Appl Pharmacol 2003;192:294-306.

12. Dohadwala M, Yang SC, Luo J, et al. Cyclooxygenase-2-dependent regulation of $\mathrm{E}$-cadherin: prostaglandin $\mathrm{E}(2)$ induces transcriptional repressors ZEB1 and snail in non-small cell lung cancer. Cancer Res 2006;66:5338-5345.

13. Mann JR, Backlund MG, Buchanan FG, et al. Repression of prostaglandin dehydrogenase by epidermal growth factor and snail increases prostaglandin E2 and promotes cancer progression. Cancer Res 2006;66:6649-6656.

14. Lucas AD, Chadwick N, Warren BF, et al. The transmembrane form of the CX3CL1 chemokine fractalkine is expressed predominantly by epithelial cells in vivo. Am J Pathol 2001;158:855-866.

15. Borish LC, Steinke JW. Cytokines and chemokines. J Allergy Clin Immunol 2003;111:S460-S475.

16. Shimizu T. Role of macrophage migration inhibitory factor (MIF) in the skin. J Dermatol Sci 2005;37:65-73.

17. Schwarz T. Mechanisms of UV-induced immunosuppression. Keio J Med 2005;54:165-171. 
18. Mantovani A, Muzio M, Ghezzi $P$, et al. Negative regulators of the interleukin-1 system: receptor antagonists and a decoy receptor. Int J Clin Lab Res 1996;26:7-14.

19. Hirao T, Aoki H, Yoshida $\mathrm{T}$, et al. Elevation of interleukin 1 receptor antagonist in the stratum corneum of sun-exposed and ultraviolet Birradiated human skin. J Invest Dermatol 1996;106:1102-1107.

20. Becherel PA, Mossalayi MD, Le Goff L, et al. IgE-dependent activation of Fc epsilon RII/CD23+ normal human keratinocytes: the role of cAMP and nitric oxide. Cell Mol Biol 1994;40:283-290.

21. Nagaoka $\mathrm{Y}$, Nakamura $\mathrm{K}$, Yasaka $\mathrm{N}$, et al. Identification and characterization of the low-affinity receptor for immunoglobulin $E$ (FcepsilonRII/CD23) on murine Langerhans cells. J Invest Dermatol 2002;119:130-136.

22. Kulms D, Pöppelmann B, Yarosh D, et al. Nuclear and cell membrane effects contribute independently to the induction of apoptosis in human cells exposed to UVB radiation. Proc Natl Acad Sci USA 1999;96:7974-7979.

23. van Oosten $\mathrm{M}$, Rebel $\mathrm{H}$, Friedberg $\mathrm{EC}$, et al. Differential role of transcription-coupled repair in UVB-induced G2 arrest and apoptosis in mouse epidermis. Proc Natl Acad Sci USA 2000;97:11268-11273.

24. Sander CS, Chang H, Hamm F, et al. Role of oxidative stress and the antioxidant network in cutaneous carcinogenesis. Int J Dermatol 2004;43:326-335.

25. Kajita M, McClinic KN, Wade PA. Aberrant expression of the transcription factors Snail and Slug alters the response to genotoxic stress. Mol Cell Biol 2004;24:7559-7566.

26. Inoue A, Seidel MG, Wu W, et al. Slug, a highly conserved zinc finger transcriptional repressor, protects hematopoietic progenitor cells from radiation-induced apoptosis in vivo. Cancer Cell 2002;2:279-288.

27. Griswold DE, Connor JR, Dalton BJ, et al. Activation of the IL-1 gene in UV-irradiated mouse skin: association with inflammatory sequelae and pharmacologic intervention. J Invest Dermatol 1991;97:1019-1023.

28. Scordi IA, Vincek V. Time course study of UVB-induced cytokine induction in whole mouse skin. Photodermatol Photoimmunol Photomed 2000;16:67-73.

29. Enk CD, Mahanty S, Blauvelt A, et al. UVB induces IL-12 transcription in human keratinocytes in vivo and in vitro. Photochem Photobiol 1996;63:854-859.
30. Hemavathy K, Guru SC, Harris J, et al. Human Slug is a repressor that localizes to sites of active transcription. Mol Cell Biol 2000;20:50875095.

31. Tribulo C, Aybar MJ, Sanchez SS, et al. A balance between the antiapoptotic activity of Slug and the apoptotic activity of msx1 is required for the proper development of the neural crest. Dev Biol 2004;275:325-342.

32. Matsumura $\mathrm{Y}$, Ananthaswamy $\mathrm{HN}$. Toxic effects of ultraviolet radiation on the skin. Toxicol Appl Pharmacol 2004;195:298-308.

33. Shibue T, Taniguchi T. BH3-only proteins: integrated control point of apoptosis. Int J Cancer 2006;119:2036-2043.

34. Wu W, Heinrichs S, Xu D, et al. Slug antagonizes p53-mediated apoptosis of hematopoietic progenitors by repressing puma. Cell 2005;123:641-653.

35. Ramirez A, Vidal M, Bravo A, et al. Analysis of sequences controlling tissue-specific and hyperproliferation-related keratin 6 gene expression in transgenic mice. DNA Cell Biol 1998;17:177-185.

36. Moreno-Bueno G, Cubillo E, Sarrio D, et al. Genetic profiling of epithelial cells expressing E-cadherin repressors reveals a distinct role for snail, slug, and E47 factors in epithelial-mesenchymal transition. Cancer Res 2006;66:9543-9556.

37. Turner FE, Broad S, Khanim FL, et al. Slug regulates integrin expression and cell proliferation in human epidermal keratinocytes. J Biol Chem 2006;281:21321-21331.

38. Bolos V, Peinado $\mathrm{H}$, Perez-Moreno MA, et al. The transcription factor Slug represses E-cadherin expression and induces epithelial to mesenchymal transitions: a comparison with Snail and E47 repressors. J Cell Sci 2003;116:499-511.

39. Bruls WA, van Weelden $\mathrm{H}$, van der Leun JC. Transmission of UV-radiation through human epidermal layers as a factor influencing the minimal erythema dose. Photochem Photobiol 1984;39:63-67.

40. Slominski A, Pawelek J. Animals under the sun: effects of ultraviolet radiation on mammalian skin. Clin Dermatol 1998;16: 503-515.

41. Young AR. Acute effects of UVR on human eyes and skin. Prog Biophys Mol Biol 2006;92:80-85. 